\title{
PREDNISOLONE MAINTENANCE THERAPY IN CHRONIC PULMONARY HEART DISEASE
}

\author{
BY \\ J. N. MICKERSON \\ From The Cardiac Department, Charing Cross Hospital \\ Received July 17, 1959
}

While the effectiveness of cortisone in the treatment of status asthmaticus has been established, the value of its continued administration in chronic asthma is disputed (Medical Research Council Report, 1956). The benefits that follow steroid maintenance therapy in chronic asthma must justify the disadvantages attending their continued administration. The hazard of salt retention has been reduced considerably since the introduction of prednisone and prednisolone in the treatment of asthma (Arbesman and Ehrenreich, 1955; Barach et al., 1955). There remain, however, other dangers associated with long-term steroid therapy, some with fatal consequences. Thus suprarenal atrophy (Kern, 1957) may account for a number of sudden unexplained deaths in asthmatic patients given cortisone over a long period (Savidge and Brockbank, 1954). Patients receiving prolonged steroid therapy are poor risks when subjected to operation or anæsthesia; they react adversely to injury and to acute infection; and steroids favour the development of peptic ulceration and not only increase the likelihood of perforation and hæmorrhage but, by suppressing the characteristic symptoms and physical signs, may prevent the detection of these complications.

Against these formidable disadvantages must be set the increasing incapacity of the chronic asthmatic whose continued existence depends upon antispasmodic drugs and antibiotics. Living in fear from one inevitable exacerbation to the next, they survive to develop chronic pulmonary heart disease. Bedridden with extreme dyspnœa and mounting dropsy, it is perhaps merciful that the mental confusion of cerebral anoxia ultimately supervenes to calm their mental distress before death relieves their brittle existence. The necessity to relieve these symptoms with steroids is as great as that to relieve the pain in cardiac infarction, for which morphine is given with confidence despite the disadvantages.

It is the purpose of this paper to describe the beneficial results of long-term prednisolone therapy and to advance a rationale for its continued administration in patients with chronic asthma, especially those complicated by pulmonary heart disease.

Material. This series comprises 4 women with bronchial asthma whose ages range from 26 to 59 years. Three of them (Cases 1, 2, and 4) had developed chronic pulmonary heart disease as indicated by the presence of a lower sternal heave, gallop rhythm, and an accentuated pulmonary second sound, associated with radiological prominence of the pulmonary conus and the cardiographic patterns of right ventricular hypertrophy and pulmonary $\mathbf{P}$ waves. Congestive heart failure had supervened in two (Cases 1 and 2) and was evidenced by jugular venous and hepatic congestion with œdema and radiological enlargement of the right ventricle. Asthmatic attacks were precipitated in each instance by infection but in two patients an additional allergic factor was present (Table I).

Certain clinical features that were common to all four patients prompted investigation of adreno-cortical function; serum electrolyte and blood urea levels were estimated and serial electrocardiograms recorded in each patient before and during steroid therapy. 
TABLE I

Patients with Bronchial Asthma. Duration of Symptoms, and Associated Complications

\begin{tabular}{|c|c|c|c|c|c|c|}
\hline $\begin{array}{l}\text { Case } \\
\text { No. }\end{array}$ & $\begin{array}{l}\text { Age } \\
\text { Sex }\end{array}$ & $\begin{array}{l}\text { Duration } \\
\text { of asthma }\end{array}$ & $\begin{array}{l}\text { Precipitating } \\
\text { factors }\end{array}$ & $\begin{array}{l}\text { Chronic cor } \\
\text { pulmonale }\end{array}$ & $\begin{array}{l}\text { Heart } \\
\text { failure }\end{array}$ & Associated conditions \\
\hline 1 & $54 \mathrm{~F}$ & $6 \mathrm{yr}$. & R.I.* & Present & $\begin{array}{l}\text { Present } \\
\quad 1 \text { month }\end{array}$ & \\
\hline 2 & $36 \mathrm{~F}$ & $8 \mathrm{yr}$. & R.I. & Present & $\begin{array}{l}\text { Intermittent } \\
18 \text { months }\end{array}$ & \\
\hline 3 & $59 \mathrm{~F}$ & $30 \mathrm{yr}$. & $\begin{array}{l}\text { R.I. and childhood } \\
\text { hay fever }\end{array}$ & Absent & Absent & $\begin{array}{l}\text { Hypertension and ischæmic } \\
\text { heart disease }\end{array}$ \\
\hline 4 & $26 \mathrm{~F}$ & $24 \mathrm{yr}$. & $\begin{array}{l}\text { R.I. and childhood } \\
\text { hay fever }\end{array}$ & Present & Absent & Pulmonary sarcoidosis \\
\hline
\end{tabular}

* Respiratory infection.

\section{Clinical Picture}

Observed over periods varying from 18 months to three years, asthmatic symptoms varied in severity, frequency, and duration in each patient. Of the two with congestive heart failure, one (Case 1) in whom congestive failure had been present for one month was incapacitated: the other (Case 2), despite digitalis and diuretic therapy with reduced dietary salt, had in the past year required hospital treatment for heart failure on two occasions, and during the previous three months had been in a state of continuous mild congestive failure with greatly restricted activities. In neither patient was the standard treatment for heart failure effective.

All four patients showed the following features that could not be attributed either to bronchial asthma or to pulmonary heart disease.

(1) Fatigue and weakness. Each experienced a sensation of considerable exhaustion and tiredness with muscular weakness. Although usually more intense during exacerbations of asthma, these symptoms fluctuated in severity independent of the asthmatic state. They were so extreme in one (Case 2) that she would fall asleep at the bus stop, while at the lavatory, or during meals; in others lethargy and weakness during intervals of freedom from asthma were of sufficient extent to interfere with routine daily activities.

(2) Pigmentation. Excessive pigmentation of the skin was present in all four patients, two having buccal pigmentation also (Cases 1 and 2).

(3) Thyroid enlargement. Slight diffuse thyroid enlargement was found in each case and in one (Case 4) a small adenoma was also present. Clinically these patients had no evidence of thyroid overactivity although one (Case 3 ) had lid retraction and lid lag.

(4) EEdema. Slight ankle œdema occurred periodically in all four patients. Although it was possibly related to congestive heart failure in one (Case 2); in another (Case 1), in whom it was associated with puffiness of the hands and face, it coincided with the onset of asthma and antedated by five years her first episode of congestive failure. That œdema was not determined by congestive heart failure was also evident by its occurrence in the two remaining patients, neither of whom had shown evidence of heart failure.

Previous experience (Mickerson, 1959; Mickerson and Swale, 1959) suggested that these features might be associated with decreased anterior pituitary activity accompanied by secondary adrenocortical deficiency. It was considered that bronchial inflammation, induced in these patients by allergy or bacterial infection alone or in combination, had created a demand for adrenocorticoids which had been supplied initially by increased pituitary activity. With persistent bronchial inflammation and exacerbations of bronchitis, prolonged demands upon the pituitary-adrenal mechanism had induced anterior pituitary exhaustion. Thus thyroid enlargement would relate to the phase 
of pituitary stimulation, while asthenia would be associated with adrenocortical insufficiency secondary to adreno-hypophyseal exhaustion. Furthermore, at this stage adrenocorticoid deficiency would permit unopposed activity of posterior pituitary antidiuretic hormone (Talbot et al., 1952) and the water retention would result in œdema formation.

\section{ADRENOCORTICAL FUNCTION}

Adrenocortical function was assessed in two patients (Cases 1 and 3) by estimation of the 24-hour urinary 17-ketosteroid and corticoid excretions; these steroid excretion levels were reestimated on the last day of a 4-day course of intramuscular corticotrophin (40 units t.i.d.). In both patients subnormal steroid excretion levels revealed adrenocortical insufficiency but the increased values obtained following corticotrophin stimulation (Table II) indicated that deficient adrenal function was due to decreased anterior pituitary activity.

TABLE II

Urinary STERoId EXCRETION BEFORE AND DURING CORTICOTROPHIN AdMinistration

\begin{tabular}{c|c|c|c|c}
\hline \multirow{2}{*}{ Case No. } & \multicolumn{4}{|c}{ Urinary excretion (mg. per diem) } \\
\cline { 2 - 4 } & \multicolumn{2}{|c}{ Before corticotrophin } & \multicolumn{2}{|c}{ During corticotrophin } \\
\hline 1 & $\begin{array}{c}\text { 17-ketosteroids } \\
3\end{array}$ & $\begin{array}{c}\text { corticoids } \\
5\end{array}$ & $\begin{array}{c}\text { 17-ketosteroids } \\
6\end{array}$ & $\begin{array}{c}\text { corticoids } \\
23\end{array}$ \\
\hline 3 & $2 \cdot 4$ & $4 \cdot 3$ & 13 & 16 \\
\hline
\end{tabular}

Serum electrolyte and blood levels were normal in all four patients before starting steroid therapy (Table III). These normal values were to be expected since normal electrolyte levels are usual in hypopituitarism, a finding that might be attributed to continued baseline aldosterone secretion independent of pituitary activity (Thorn et al., 1957).

TABLE III

Serum Electrolyte and Blood Urea Estimations before Prednisolone Therapy

\begin{tabular}{c|c|c|c|c|c}
\hline $\begin{array}{c}\text { Case } \\
\text { No. }\end{array}$ & $\begin{array}{c}\text { Serum Na } \\
\mathrm{m.eq} / \mathrm{l} .\end{array}$ & $\begin{array}{c}\text { Serum K } \\
\mathrm{m.eq} / \mathrm{l} .\end{array}$ & $\begin{array}{c}\text { Serum chlorides } \\
\mathrm{m.eq} / \mathrm{l} .\end{array}$ & $\begin{array}{c}\text { Serum alkali reserve } \\
\mathrm{m.eq} / \mathrm{l} .\end{array}$ & $\begin{array}{c}\text { Blood urea } \\
\mathrm{mg} / 100 \mathrm{ml} .\end{array}$ \\
\hline 1 & 137 & $4 \cdot 6$ & 92 & $38 \cdot 4$ & 49 \\
\hline 2 & 142 & $5 \cdot 0$ & 91 & $35 \cdot 7$ & 30 \\
\hline 3 & 145 & $5 \cdot 5$ & 103 & - & 32 \\
\hline 4 & 139 & 4.9 & 103 & - & 30 \\
\hline
\end{tabular}

\section{LONG Term Steroid TheraPy}

Apart from the necessity to relieve symptoms, it was considered that these patients had hypoadrenocorticism and that they required steroid substitution therapy to correct the deficiency. As a supplement to existing therapy, prednisolone was administered in physiological dosage (7.5 to $12.5 \mathrm{mg}$. daily) to the three patients whose bronchial asthma was complicated by pulmonary heart disease. Those previously receiving a restricted sodium diet were given a normal diet.

Improvement occurred in each patient within a few days of starting steroid therapy; fatigue and muscular weakness vanished and dyspnœa subsided. An increased sense of well being was 
matched by objective evidence of improvement. Rhonchi disappeared or were greatly reduced on auscultation of the chest, and in those with cardiac failure which had previously been uninfluenced by standard treatment, a diuresis occurred (Fig. 1), venous congestion subsided, and heart failure was relieved within one week of starting prednisolone.

Following relief of symptoms and heart failure, prednisolone therapy was continued in physiological amounts and patients were observed for periods varying from 9 to 18 months. With such small steroid dosage in subjects whose endogenous steroid production was subnormal, it was hoped to avoid the development of peptic ulceration and its fatal complications, acute psychoses, and osteoporotic fractures, and also any possibility of encouraging infection. Indeed none of these complications occurred although Case 4 had a proven duodenal ulcer and a history of severe hæmorrhage two years previously. Patients were given a reserve supply of prednisolone with instructions to increase their daily dosage by 5 to $10 \mathrm{mg}$. should they develop infection and to report to the hospital. They were warned of the potential dangers of accidents and anæsthetics and told that necessary dental extractions should be done in hospital. Two attacks of bronchitis accompanied by asthma did occur in Case 1 but each was quickly relieved by increasing the dosage of prednisolone to $30 \mathrm{mg}$. daily and simultaneously administering tetracycline for five days. This patient also experienced occasional episodes of increased tiredness and weakness; these subsided when the prednisolone dosage was temporarily increased to $25 \mathrm{mg}$. daily and within three or four days she was able to revert to her previous dosage.

No attempt was made to combat the adrenal atrophy that develops during prolonged steroid therapy. The suggestion of Ungar and Johnson (1957) that periodic courses of A.C.T.H.-gel be given to stimulate the adrenals during such therapy might have overcome this possible hazard.

With long continued prednisolone administration and a normal dietary sodium, slight salt retention occurred. This was prevented either by reducing the dietary salt or by giving chlorothiazide $0.5 \mathrm{~g}$. twice daily combined with potassium chloride $2 \mathrm{~g}$. daily, for
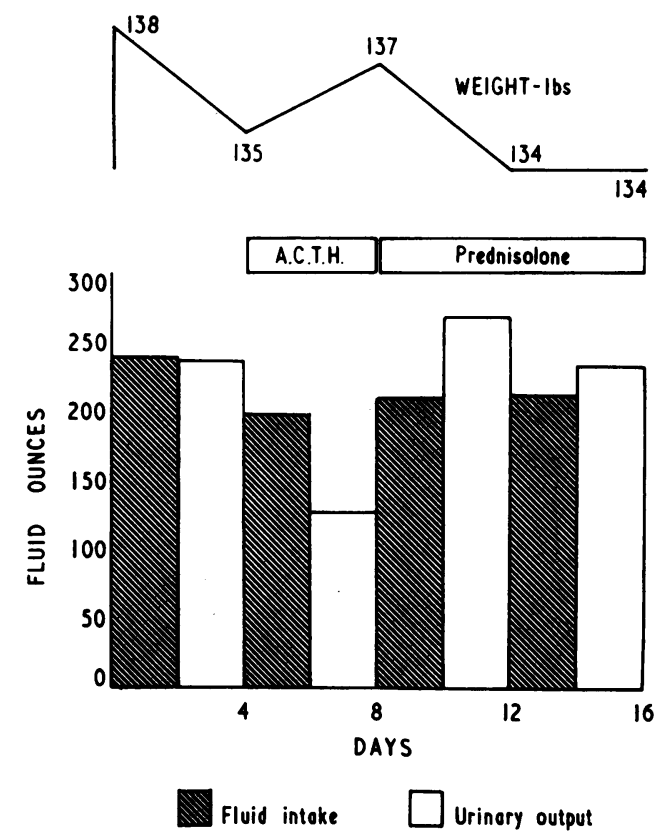

FIG. 1.-Prednisolone-induced diuresis. Total four-day fluid volumes during initial control period, corticotrophin administration, and treatment with prednisolone. (The reduced urinary excretion during corticotrophin administration was attributed to unavoidable contamination of A.C.T.H. by antidiuretic hormone.) Case 2.

two days each week. After trying each alternative the latter was preferred by all three patients.

During the period of observation the improvement was maintained and pulmonary symptoms and signs relieved. Those in whom heart failure had previously occurred suffered no recurrence and it was possible to omit digitalis from their therapeutic regimen. The three patients with chronic cor pulmonale were enabled to resume a normal mode of life.

Serial electrocardiograms taken before and during treatment with prednisolone provided indisputable evidence of improvement. The initial cardiograms were recorded when patients were free from either bronchial infection or heart failure. In each instance pulmonary $P$ waves indicated the presence of pulmonary hypertension and in Cases 2 and 4 the patterns of right ventricular strain were present. After treatment with prednisolone for varied intervals the cardiograms were repeated: all tracings showed a decreased $\mathbf{P}$ wave voltage with normal $\mathbf{P}$ waves replacing the previously recorded pulmonary $\mathbf{P}$ waves and there was also evidence of lessened right ventricular strain (Fig. 2-4). 


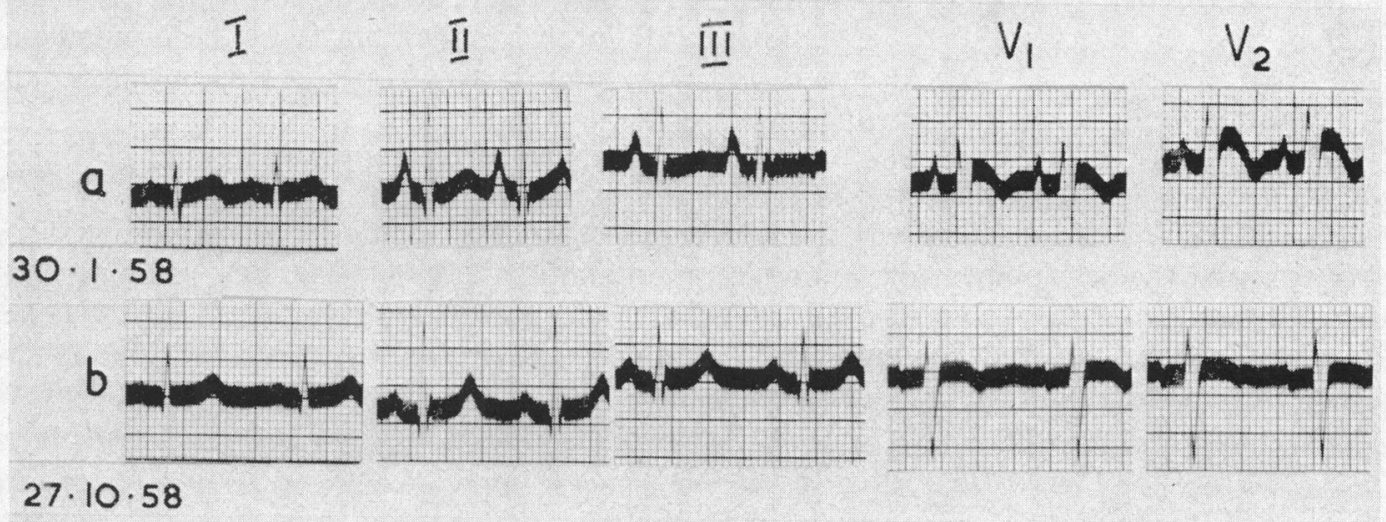

FIG. 2.-Electrocardiograms ( $a$ ) before, and (b) after ten months' prednisolone therapy. Case 1.

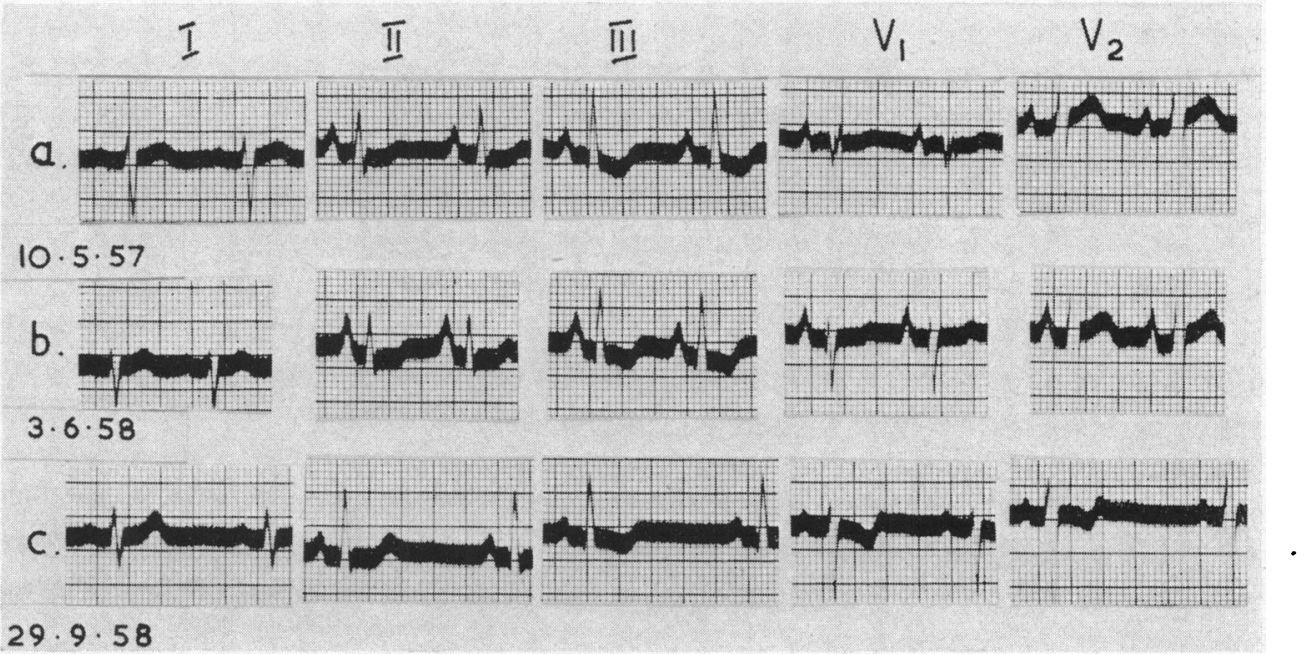

Fig. 3.-Electrocardiograms ( $a$ and $b)$ before, and $(c)$ after three months' prednisolone therapy. Case 2.

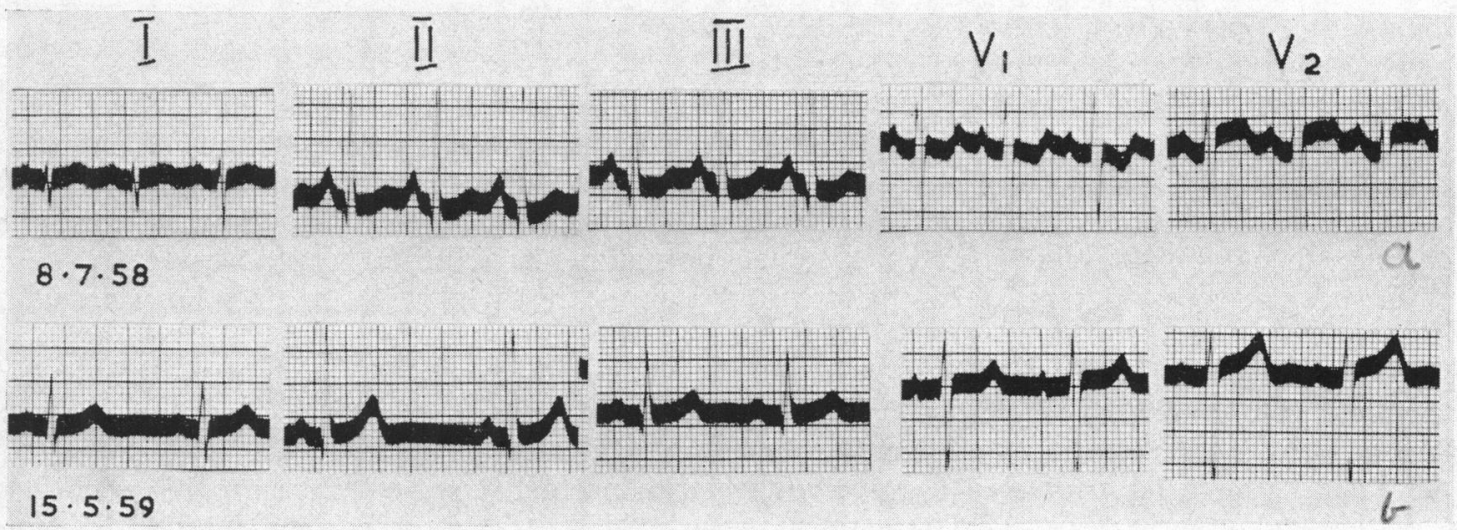

FIG. 4.-Electrocardiograms (a) before, and (b) after nine months' prednisolone therapy. Case 4. 


\section{Discussion}

The improved cardiac function that occurred in these patients, two of whom were relieved of heart failure, together with the regressive cardiographic patterns, were attributed to the following two factors.

(1) Improved Oxygenation. By improving pulmonary ventilatory capacity (Thursby-Pelham and Kennedy, 1958) prednisolone increases oxygenation and will relieve or reduce the hypoxia associated with chronic asthma, thereby reducing pulmonary arterial pressure (Von Euler and Liljestrand, 1946; Wood, 1958).

(2) Decreased Respiratory Activity and Lowered Intra-alveolar Tension. The respiratory pump by varying the stroke output of the right ventricle influences pulmonary arterial pressure. Increased fluctuations of this associated with pulmonary hypertension and congestion have been reported in patients with chronic pulmonary heart disease by Rodbard et al. (1956). They attributed these wide fluctuations to the greater resistance to air flow and reduced lung compliance leading to increased respiratory excursions in chronic pulmonary disease. In addition the increased intra-alveolar pressure occurring in bronchial asthma will be communicated to the pulmonary capillaries, increasing pulmonary vascular resistance and thereby increasing pulmonary arterial pressure. While the relief of dyspnœa by prednisolone will reduce respiratory efforts, the synchronous increase of pulmonary ventilatory capacity must be associated with a decrease of intra-alveolar pressure, thereby reducing pulmonary arterial pressure.

Thus prednisolone therapy will improve oxygenation, and, by correcting the adverse pulmonary hæmodynamic conditions relieve the work burden of the right ventricle in chronic pulmonary heart disease. It is essential that such therapy be started before secondary emphysema has advanced too far to allow a decrease in respiratory effort and intra-alveolar pressure and before extensive pulmonary atheroma has developed. Pulmonary hypertension, induced by impaired pulmonary ventilation in bronchial asthma, is likely to be permanent and progressive unless the ventilatory capacity can be increased. The presence of cardiographic pulmonary $\mathbf{P}$ waves should therefore be an indication for continued prednisolone therapy in chronic asthmatics.

In addition to the need for improving respiratory function there are further reasons for steroid maintenance therapy in certain patients with chronic asthma and cor pulmonale. In a previous paper (Mickerson and Swale, 1959) evidence has been presented to suggest that heart failure is initially associated with pituitary stimulation and that ultimately, with continued heart failure and prolonged hypophyseal activity, anterior pituitary exhaustion occurs. At this stage in chronic heart failure, odema is encouraged by persistent excessive posterior pituitary stimulation, co-existent with a deficiency of glucocorticoids; the increased anti-diuretic hormone activity, unantagonized by adrenocorticoids, resulting in primary water retention.

All four patients in the present series had symptoms and signs suggesting this sequence of endocrine adjustment, and biochemical evidence supported the hypothesis of their having reached a state of pituitary exhaustion. The diuresis and loss of weight that occurred (Fig. 1) following prednisolone administration have been recorded previously by Bickerman et al. (1955) who observed a diuresis and weight loss in 5 of 30 patients with bronchial asthma and in 12 to 50 patients with pulmonary fibrosis when treated with prednisone. According to Mickerson and Swale (1959) prednisolone replacement therapy would restore the antagonism that normally exists between adrenocorticoids and antidiuretic hormone and thus encourage diuresis.

These findings suggest that anterior pituitary insufficiency with secondary hypo-adrenocorticism occurs in some patients with bronchial asthma and chronic cor pulmonale, and they provide further justification for long.term steroid maintenance therapy. 


\section{SUMMARY}

Prednisolone was administered to four patients with bronchial asthma, three having chronic pulmonary heart disease, for periods of from 9 to 18 months. Co-existent heart failure was relieved and all three were maintained free from symptoms and unrestricted in their activities. Serial electrocardiograms showed a decrease in $\mathbf{P}$ wave voltage, with reversion of pulmonary $\mathrm{P}$ waves to normal, and reflected improvement in the pulmonary hæmodynamics during steroid therapy.

Evidence is presented to justify steroid maintenance therapy in patients with bronchial asthma and chronic cor pulmonale. The presence of pulmonary $\mathbf{P}$ waves in cardiographic tracings in such patients is considered an indication for long-term prednisolone therapy.

Possible reasons are discussed for the beneficial effects of prednisolone in asthmatic patients with pulmonary heart disease.

I thank Dr. K. Shirley Smith and Dr. N. S. Plummer for permission to investigate their patients and Dr. Shirley Smith for his helpful criticism. I am indebted to Professor Patterson and Dr. Swale for the steroid excretion estimations. Miss Anne Smith kindly supplied the cardiographic tracings and Miss Turnbull the chart.

\section{REFERENCES}

Arbesman, C. E., and Ehrenreich, R. J. (1955). J. Allergy, 26, 189.

Barach, A. L., Bickerman, H. A., and Beck, G. J. (1955). Dis. Chest, 27, 515.

Bickerman, H. A., Beck, G. J., and Barach, A. L. (1955). J. Chronic Dis., 2, 247.

Euler, V. S. Von, and Liljestrand, G. (1946). Acta physiol. scand., 12, 301.

Kern, R. A. (1957). Trans. Coll. Physn. Philad., 25, 8.

Medical Research Council (1956). Lancet, 2, 798.

Mickerson, J. N., and Swale, J. (1959). Brit. med. J., 1, 876.

(1959). Lancet, 1, 1118.

Rodbard, S., Kariv, I., and Heiman, D. F. (1956). Amer. Heart J., 52, 182.

Savidge, R. S., and Brockbank, W. (1954). Lancet, 2, 798.

Talbot, N. B., Sobel, E. H., McArthur, J. W., and Crawford, J. D. (1952). Functional Endocrinology, p. 516. Harvard University Press, Cambridge, Mass.

Thorn, G. W., Rose, E. J., Crabbé, J., and Van't Hoff, W. (1957). Brit. med. J., 2, 955.

Thursby-Pelham, D. C., and Kennedy, M. C. S. (1958). Brit. med. J., 1, 243.

Ungar, L., and Johnson, J. H. (1957). Ann. Allergy, 15, 563.

Wood, P. (1958). Brit. Heart J., $20,557$. 